\title{
Personnel performance assessment in information systems outsourcing environments
}

\author{
Cristina Casado Lumbreras
}

Faculty of Education, Universidad Complutense de Madrid, Madrid, Spain

Pedro Soto Acosta

Department of Management \& Finance, University of Murcia, Murcia, Spain

Ricardo Colomo Palacios

Computer Science Department, Carlos III University, Madrid, Spain, and

Patricia Ordóñez de Pablos

Department of Business Administration, Faculty of Economy and Business, University of Oviedo, Oviedo-Asturias, Spain

\begin{abstract}
Purpose The aim of this paper is to present a tool which uses semantic technologies for personnel performance and workplace learning assessment in outsourced information technology environments. Design/methodology/approach The paper presents the tool from a technical perspective and introduces a use case that depicts the main features related to human resource management issues.

Findings Semantic technologies enable the monitoring of personnel throughout all of the phases of the management of outsourcing, basing itself on established communication standards used in leading business management tools and recent outsourcing efforts. This monitoring provides to human resource management issues an integrated approach to assess both employee performance and learning outcomes as a result of competence evaluation.

Originality/value The paper shows that semantic technologies can be applied to human resource management tools to bring its intrinsic characteristics to human resource management tasks including personnel and learning assessment.
\end{abstract}

Keywords Outsourcing, Semantic web, Information system outsourcing,

Personnel performance assessment, Information technology

Paper type Technical paper

\section{Introduction}

In an environment of globalization and competition, institutions have turned to knowledge as a strategic asset that drives sustainable economic advantage (Sharma et al., 2010). And as a consequence of this the development of intellectual capital of corporations represents one of the most significant challenges for today's managers and

Paper presented at the 3rd World Summit on the Knowledge Society (WSKS 2010, Corfu, Greece, September 22 24, 2010) 
one of the most fertile fields for business innovation, human resource management and education research (Casado-Lumbreras et al., 2010). In this environment, the power of knowledge in our contemporary life has produced many new terms and concepts including: "knowledge society"; "knowledge economy", "knowledge management" and "knowledge culture" (Bakry and Alfantookh, 2010). Drucker (1998) stated that knowledge is the most significant economic resource of a post-capitalist society. As a consequence, many companies have opted for a model in which knowledge is a fundamental element of corporate and operational strategy. This has led to the formation of definitions such as knowledge intensive organizations (KOI), which, according to Starbuck (1992), are those organizations in which "knowledge plays a more important role than any other of the inputs to an organization". According to the work of Karreman et al. (2002), KOIs exhibit the following characteristics:

- Personnel are highly qualified and hold university qualifications or a comprehensive professional qualification.

- Products and services are complex and not standardized.

- The product, the market and staff development are regarded as significant activities within the organization.

Managerial organizations, which display characteristics of KOIs include, among others, legal services, strategic consulting companies, software engineering organizations, re-search agencies and other technology-based organizations (Hurley and Green, 2005). In such a setting, employees of software engineering companies, which are the subject of the current research, may be termed "knowledge workers", a phrase coined by Peter Drucker (1959). The growth of the Internet has provoked a change in the working environment of all employees, in particular knowledge workers. Thus, new technological capacities greatly benefit the outsourcing of the processes in the networked enterprise, which is transforming current society into an e-Society. In these societies, knowledge must present a tacit structure for sustainable advantage (Sharma et al., 2010). Given this requirement, competences and competence structures for information technology (IT) professionals can be seen as enablers for the Knowledge Society, needed also of intellectual capital and competent IT workers (Hernández-López et al., 2010). Human capital is particularly critical for competitiveness in high-tech sectors (Bartelsman et al., 2004) and more in particular in IT sector (Trigo et al., 2010). Moreover, IT has been considered fundamental for the development of productivity and knowledge-intensive products and services (Soto-Acosta et al., 2010).

The key role of IT has obliged an increase in the importance of human capital in general and its evaluation. IT workers professional practice must be continually revised and improved in order to adapt workers competences' to technical innovations and soft skills to evolving markets (Casado-Lumbreras et al., 2009). Moreover, IT organizations, who frequently lead the development of change based around ICT, are being asked to develop new products and services that add significant value for customers and to radically change their internal processes so that they are more cost effective (O'Sullivan and Dooley, 2010).

Taking into account that the use of competency frameworks as a basis for workplace learning initiatives is now relatively commonplace in organizations (McGuire, 2001), competency assessment can be seen as a key enabler to workplace learning assessment. Moreover, Garavan and McGuire (2001) emphasized the need to develop consensus 
on definitions of competence if it is to contribute to more effective workplace learning. There is a growing awareness that recognition of adult learning cannot be restricted to learning which occurs in formal settings (Owen and Stupans, 2009) and workplace learning must be assessed in order to keep track of employees' development, no matter where they are. In outsourcing scenarios, different cultures and organizations are mixed and factors considered critical for the effectiveness of workplace learning (e.g. organizational learning culture (Rebelo and Duarte Gomes, 2011)) vary in a considerable amount. In IT picture, there are several works reporting that software engineers did not find formal courses efficient to acquire application-domain knowledge and most employees learn how to solve a problem at hand informally from peers (Johnson and Senges, 2010). In such setup, instruments that detect learning needs, learning outcomes and assess the overall performance of a worker could be a competitive advantage for the company.

In an environment supported by the Semantic Web, the aim of the tool presented in this paper is that workers in outsourcing environments, client organizations and contractors benefit from the capacities of PAIS-OUT to avail of an open environment for management and evaluation of performance in outsourcing environments. Thus, PAIS-OUT permits the monitoring of outsourced personnel development activities including formal and informal learning outcomes.

\section{State of the art}

This section reviews the state of the art of the solution. Thus, first, semantic web technologies, which are the cornerstones of PAIS-OUT are outlined. In the second term, a functional description of outsourcing is provided, as well as an outline of the principal initiatives which regulate the relation between the provider of the outsourcing services and the contracting organization. Finally, the principal features of the evaluation of personnel are presented.

\subsection{Semantic technologies}

Semantic technologies provide a consistent and reliable basis to face the challenges for data and knowledge organization, manipulation and visualization. As a result of this, the possibility of using knowledge-oriented query answering methods to exploit the benefits of semantics is a key research issue. The term "semantic web" was coined by Berners-Lee et al. (2001) to describe the evolution from a document-based web towards a new paradigm that includes data and information for computers to manipulate. The goals of the semantic web initiative include the integration of data from different sources in a machine processable format in order to make them accessible to computer programs and facilitating the use of data in ways that have not been thought of when the data were entered or recorded (Battré, 2008). It is agreed that semantic enrichment of resources would lead to better search results (Scheir et al., 2008). In this new scenario, the challenge for the next generation of the social and semantic webs is to find the right match between what is put online and methods for doing useful reasoning with the data (Gruber, 2008).

Besides, semantic web, ontology defines a set of representational primitives with which a domain of knowledge is modelled. Ontologies (Fensel, 2002) are the technological cornerstones of the semantic web, because they provide structured vocabularies that describe a formal specification of a shared conceptualization (Gruber, 1994). The semantic 
web provides an alternative solution to represent the comprehensive meaning of integrated information and promises to lead to efficient data managing by establishing a common understanding (Shadbolt et al., 2006). The semantic web is about annotating information so that both computer systems and humans can process it more meaningfully (Davies et al., 2007). Given its capacity to provide the meaning of information, the Semantic Web, has been identified as a valid context for knowledge management (Vossen et al., 2007), being described as "a brain for humankind" (Fensel and Munsen, 2001).

Given the importance of semantic technologies in many areas (García-Crespo et al., $2010 \mathrm{a}, \mathrm{b})$ and the crucial impact of workforce in IT environments, there are several works that gather both worlds. Semantic technology has been applied for project management teams construction (Gómez-Berbís et al., 2008), knowledge management for software projects (Colomo-Palacios et al., 2008), benchmarking personnel metrics (García-Crespo et al., 2009a), technical competence assessment (Colomo-Palacios et al., 2010), knowledge sharing and reuse (Lanzenberger et al., 2008), assist the learning process (Naeve et al., 2008) or support work assignment (Macris et al., 2008) to cite some of the most recent initiatives.

In outsourcing environments, these types of initiatives for interaction using the semantic web can also be seen, however, they are significantly fewer in number. Kim et al. (2006) propose to use semantic web services for the automated outsourcing partnership management. García-Crespo et al. (2009b), in an effort which is considered the ancestor to the current work, proposed a semantics-based environment for the selection of stable partners for trustworthy innovation outsourcing processes. With the objective of extending previous proposals, this paper presents PAIS-OUT, a semantic environment based on the application of state of the art practices of personnel assessment in outsourcing environments, applicable to the lifecycle of this successful business practice. In what follows, an explanations of the functional area of PAIS-OUT will be provided.

\subsection{Outsourcing}

Outsourcing describes the use of external resources to execute operational tasks (Grover et al., 1994). Zineldin and Bredenlow (2003) pointed out that outsourcing must not be seen merely as the firm's acquisition of products and services for the manufacture of goods and provision of services, but as a particular form of strategic alliance. In the past, the corporate activities, which were the subject of outsourcing constituted mechanical activities, or processes with low added value, however, currently many business processes are outsourced (Hoecht and Trott, 2006). The two main actors of outsourcing processes are the "outsourced" and the "outsourcer" (Saunders and Gebelt, 1997). The first, i.e. the "customer", outsources his processes, while the second, the enterprise, delivers outsourced services.

The benefits of outsourcing outlined in the literature are various: economies of scale (Zineldin and Bredenlow, 2003), reduction of operational costs (Lacity and Hirschheim, 1993), access to a skilled workforce (Kakabadse and Kakabadse, 2002), shorter lead times, in-creased flexibility and cost efficiency (Nieminen and Takala, 2006), and the ability to transform fixed costs into variable costs (Alexander and Young, 1996). On the other hand, there are other works that show risks: hidden costs (Barthelemy, 2001), supplier dependency (Alexander and Young, 1996) and loss of know-how (Doig et al., 2001), to cite the most significant ones. In this scenario, 
outsourcing represents an opportunity as well as a challenge to many organizations (Barden-Fuller et al., 2005).

Information system (IS) outsourcing can be defined as the significant contribution made by external providers of physical and/or human resources, associated either with all components or with IT infrastructure specific components in the user's organization (Loh and Venkatraman, 1992, p. 9). Literature situates the beginning of outsourcing in1991, subsequent to the success achieved by Eastman Kodak with the outsourcing of its IS (Applegate and Montealegre, 1991) followed by other cases such as Continental Bank (Huber, 1993), and BP (Cross, 1995).

According to Faisal and Banwet (2009), the most important reason for IS outsourcing is the organizations' focus on their core competence while other reasons include controlling investments, attaining technological flexibility, reducing staffing problems and coping with the fast pace of growth in information and communications technologies. Outsourcing can also help a company get better, more state of the art services than it could afford internally, and this is a commonly stated reason for outsourcing IT (McDougall, 2004). It is important to highlight that, according to Beasley et al. (2009), the value impact of strategic intent on firms engaged in IS outsourcing is higher with short-term operational intent rather than for longer term strategic reasons.

Owing to these affirmations, the reasons for the adoption of outsourcing during its almost 20 years of existence have been various. Gonzalez et al. (2005) present a background to the literature for outsourcing reasons. A deeper view about IS outsourcing life cycle can be found in the work of Chou and Chou (2009).

The importance of outsourcing in the literature has been reflected in the efforts to extend the balance scorecard to include a fifth perspective to hold the business processes subject to outsourcing (Goyal and Metri, 2008), to establish maturity models for outsourcing relations (Gottschalk and Solli-Sæther, 2006) and in a much more advanced effort, eSourcing Capability Model (eSCM)-CL, a model of capacities for the management of the contracting of ICT staff in client organizations of services (Hefley and Loesche, 2006).

In relation to personnel in externalization environments, on some occasions, outsourcing implies the movement of the IT personnel from the client organization to the supplier organization (Lee et al., 2003). There are numerous examples of individuals being involuntarily transitioned from the client organization to the service provider, a model referred to as "lift-out" (Fisher et al., 2008). In these type of environments, Kessler et al. (1999) indicated that such movements can provoke both negative reactions from the workers due to dissatisfaction (dress code, type of employment, etc.) as well as increased satisfaction (enhanced career development).

Additionally, this option presents a major risk, and for the client organization, however, reduces the risk of lack of functional expertise in the client organization, identified by Earl (1996). This advantage entails an implicit risk at the time of contract renewal. An unsatisfied client may wish to repatriate the service, but repatriation may be very expensive, resulting in an unviable return (O'Leary, 1990). In this environment, the client organization needs to control the professional evolution of the personnel, with the double objective of reacting to a possible change in provider, with regard to changes in services or a new outsourcing contract. Thus, the client organization should know, by means of personnel performance assessment, the grade of development of the key resources involved in the outsourcing labor. 


\subsection{Personnel performance appraisal}

The monitoring of workers stands at the heart of the employment relationship (Brown and Heywood, 2005). Thus, performance appraisal is a delicate issue (Myloni et al., 2004). Cole (2001, p. 798) defines performance appraisal as a formalized, systematic assessment and discussion of an employee's performance and his/her potential and desire for development and training. Performance appraisal usually involves "evaluating performance based on the judgments and opinions of subordinates, peers, supervisors, other managers and even workers themselves" (Jackson and Schuler, 2003, p. 455). According to Curtis et al. (2001), the role of performance appraisal as a part of performance management is primarily to record the results of performance for use as input to decisions about adjustments to compensation, personal development planning, staffing, promotion and other workforce activities. In this way, performance appraisal is the central point for the collection of data which underlie decisions regarding the competency of human assets in their activities, requiring, on the one hand, the definition of the elements for comparison with established performance standards, and on the other hand, mechanisms put into place for the storage and exploitation of performance information.

According to Ball and Harris (1982), IS personnel evaluation is the second most critical issue of IS management. Perhaps, for this reason, the literature has discussed the difficulty of developing software systems and evaluating IT personnel in the organization for more than 40 years (Boyd et al., 2007).

Personnel performance assessment in outsourcing environments presents a double challenge. On the one hand, examining Fisher et al. (2008) the assessment of employees working on the client site represents a common outsourcing challenge. While for the client organization, the challenge "appropriateness of hiring service-provider employees" presents itself, as well as the requirement to depend on information regarding the performance of its employees, both lifted-out and new, with the objective of guaranteeing continuity of services.

\section{PAIS-OUT: internals}

The main aim of the system proposed in this paper is to assist in the assessment of IT personnel in outsourcing environments. This section presents the principal characteristics of PAIS-OUT. To do so, in the first place, the architecture of PAIS-OUT is presented, in the second place, implementation issues are presented and discussed. This section concludes with a use case to illustrate the functioning of the tool in an applied scenario.

\subsection{Architecture}

This section presents the PAIS-OUT architecture, a three layer software architecture, which partitions the functionality of the system into graphical user interface (GUI), Business Logic and Persistence and Storage Systems level. Each level has a different functionality to deal with the various challenges the system faces by means of semantic technologies. The architecture of PAIS-OUT is a metadata-driven context-aware architecture, where each component addresses a particular software requirement. The final architectural approach is a tailor-made value-added technological solution. Components might be related to the behaviour as specified in the collaboration among those elements, turning those structural and behavioural 
elements into progressively larger subsystems and the architectural style that guides this organization. The PAIS-OUT architecture is composed of the following layers:

(1) Interface. It is the entry point of the user interaction. It consists of a web-based interface which allows the user to either retrieve information through the Retrieval Component and the Update Component, which allows adding significant information regarding the Outsourcing and Competence requirements. It presents two modules:

- Retrieval component. It implements the GUI to perform partner retrieval.

- Update component. This module is a component responsible of updating competence descriptions of companies stored in the persistence layer.

(2) Logic. This layer provides cutting-edge functionalities through the following components:

- Outsourcing knowledge base (OKB). The OKB stores structured and knowledge aware outsourcing related projects, tasks, organizations and teams. It enables complex query mechanisms based on semantic technologies, but it is especially sensitive to competence ontologies, which can provide value-added results about companies willing to rent, or simply delegate their services in third parties.

- Competence manager. Enabling competence based search and description of resources is a key feature of the PAIS-OUT architecture. Both the OKB and the business rules engine (BRE) are interrelated through this component, whose formal enactments of Competences through semantic descriptions are vital for the correct processing of the information. Is responsible of dealing with competence ontology and stores information of competence evidences in the persistence layer.

- BRE. This engine is both a query engine which enables RDF-based queries into the semantic storage system and also a rules engine for the DOAP semantic descriptions. The BRE can work with the SPARQL Query Language for RDF, but also with raw SQL queries into the database underlying the persistence layer.

(3) Persistence. Both the competences ontology repository and the outsourcing ontology repository are built on a single software component, the persistence layer. This layer is based on an RDF-based repository enabling semantic querying and offering a higher abstraction layer to enable fast storage and retrieval of large amounts of RDF triples, while keeping a small footprint and a lightweight architecture approach. For the current implementation, the OpenRDF Sesame RDF storage system has been selected, as can be shown in the implementation section (Figure 1).

\subsection{Implementation}

The implementation of the architecture of PAIS-OUT is based on Sun Microsystems J2EE (Java to Enterprise Edition) technology. The communication of the different software components is based on the standard J2EE communication mechanisms, despite it could also be based on more decoupled frameworks such as web services. 


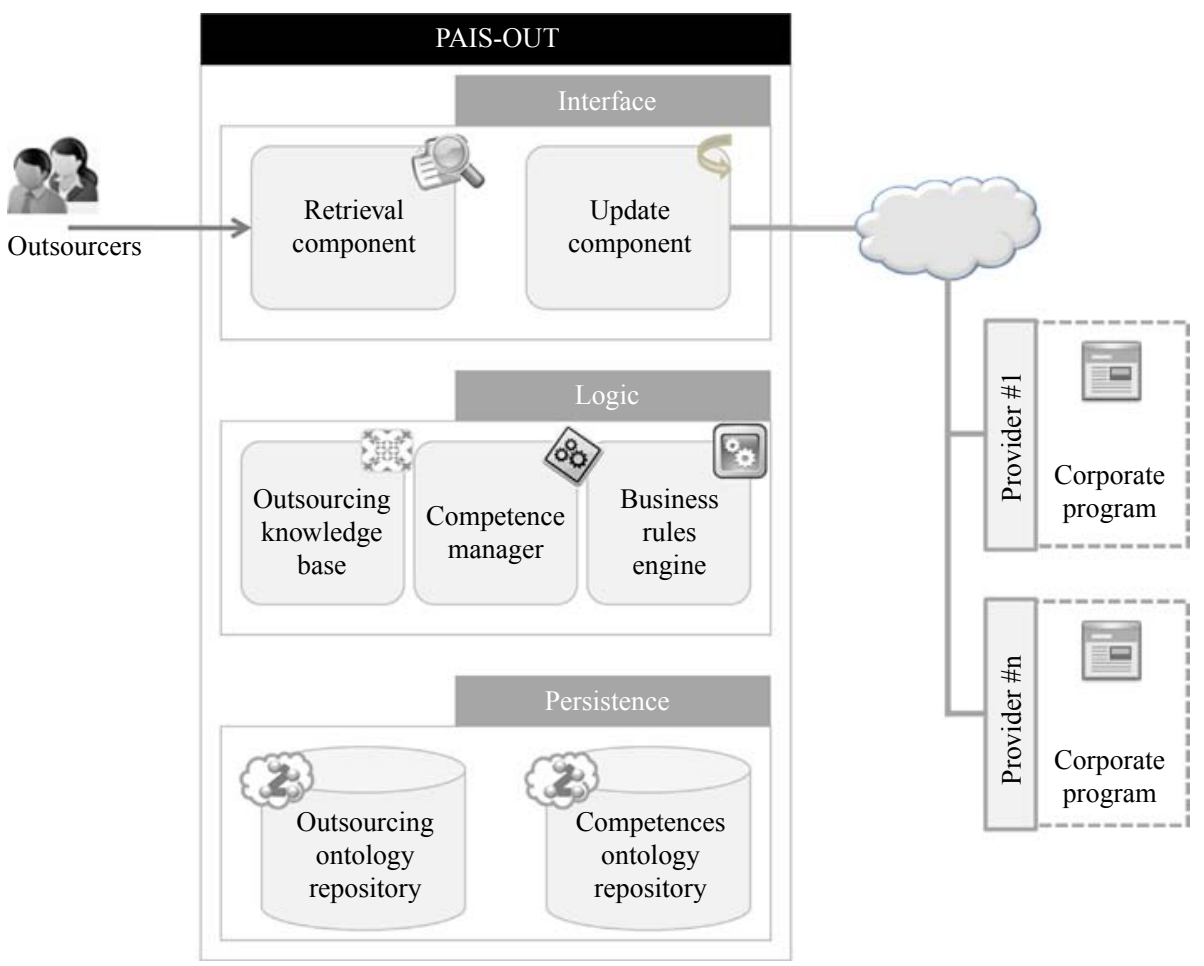

Figure 1.

PAIS OUT: architecture and interfaces

From the perspective of semantic technologies, several tools are included in PAIS-OUT. In the first term PAIS-OUT implements, the Web Ontology Language (OWL). OWL is the de facto semantic web standard language, has been used to represent the domain knowledge. OWL provides a formal theory for taxonomy, whereas any other semantic relationship like partonomy or topology must be manually defined and implemented. PAIS-OUT implements OWL-Description Logics (DL), since it builds on the formal foundations of DL (Baader et al., 2003), a set of languages whose reasoning can be decidable. Second, the Java-based Renamed ABox and Concept Expression Reasoner (RACER) is used. RACER reasoning engine and the Jena framework are the backbone technology for the Business Logic Manager layer, the former for the reasoning and the latter for the RDF Management and SPARQL Querying. The repository has been implemented using the persistence capabilities of the Jena Semantic Web Framework over SESAME.

\subsection{Use case}

The use case scenario involves a company which aims to subcontract the evolution of its application for stock management. UNLOBLIM is a company located in Liverpool, UK. This company currently uses an application developed in an IBM AS-400 environment. Two years ago, the company contracted the services of a consultancy firm for the development of ICT products located in London, however, due to a crisis in the markets and the quantity of business debtors, these operations had to close. The only current 
remaining application in the company which still requires migration to a modernized environment based on web services is the stock management application.

Making some enquiries, the management of UNLOBLIM ascertains that their previous provider was solely a set of businesses who sold solutions and services which they later subcontracted to companies in China or India. The management of UNLOBLIM is thus presented with two possibilities for the solutions to their problem. In the first place, they could contract development specifically for the application, and in the second place, carry out total outsourcing of its ICT processes. The managers decide to adopt the second option, namely offshore outsourcing. In order to effectively undertake the outsourcing process, UNLOBLIM implant the PAIS-OUT platform in search for companies, which fulfill the criteria for both functional and technical competences. Availing of the capacities of the tool, they search for companies, which offer outsourcing services in their business area. PAIS-OUT provides two companies, which meet company requirements. One of the companies is located in Birmingham (UK) and the other in Dublin (Ireland). Examining the search criteria, both businesses hold experience in outsourcing, and examining the information displayed by the DOAP registries, have the functionalities and technical expertise required by UNLOBLIM. From the perspective of the capacities of its workers, and given the fact that the information regarding corporate experience is significant, the company in Birmingham named OUTTOTAL results more suitable subsequent to evaluation. This initiates the outcome that UNLOBLIM choose to subcontract the services of this West Midlands company.

Thus, as part of the agreement, two employees from UNLOBLIM are transferred to Birmingham in a classic "Lift-Out" operation. Throughout the outsourcing relationship, UNLOBLIM participates in the evaluation of the performance of OUTTOTAL, by means of the users of the ICT service. The evaluation of the performance of the employees of the company is included as part of the evaluation, as well as the performance of the two employees taking part in the "Lift-Out" operation. The $360^{\circ}$ feedback data are available to UNLOBLIM, enabling them, on the one hand, to feed PAIS-OUT's database, and on the other hand, keep up to date with the progress of the transferred workers of the "Lift-Out" operation. This fulfills their objective of maintaining control of their workers with a view to a possible employee repositioning or a change in provider.

\section{Conclusions and future work}

In the IT domain, corporations are adopting outsourcing and offshoring models, each time more carefully. In this environment, sharing and taking advantage of a number of information sources, tracing skills, experience and expertise in different fields can bridge the gap of knowledge integration between outsourcing actors. New forms of knowledge extraction and expert location are deeply impacting companies around the world. IT companies are facing a war for talent in which, every project must be scheduled according to the availability of resources and their competences. Having this in mind, tools that seek for competence in these kinds of organizations are seen as knowledge enablers and could be also a competitive advantage for the company.

In this work, we have presented a tool to achieve personnel performance assessment in outsourcing environments using semantic technologies. However, limitations of this work should not be ignored. The first limitation is the descriptive nature of the paper. 
Therefore, a useful extension of the paper would be to carry out an empirical study of the implementation of the tool. This study will permit an analysis of its improvement in performance and the decrease in the rates of staff rotation and absenteeism in subcontracting environments. The second big limitation is the limited scope of the tool. Thus, in the first place, it is aimed to include tools, which enable automatic analysis of the competencies of the workers, based on the opinions of users expressed in Web 2.0 tools, which would be utilized internally within the organization. Finally, it is aimed to expand the system in order to collect evidences of competence of outsourced workers. These evidences of competence can be seen as the cornerstones of the evaluation, feeding the system with material in which assessment can be built. Possible sources of these data can be found among software artifacts: programs, designs, requirements, to cite the most relevant ones.

\section{References}

Alexander, M. and Young, D. (1996), “Outsourcing: where's the value?”, Long Range Planning, Vol. 29 No. 5, pp. 72830.

Applegate, L. and Montealegre, R. (1991), Eastman Kodak: Managing Information Systems Through Strategic Alliances, Harvard Business School Publishing Division, Cambridge, MA.

Baader, F., Calvanese, D., McGuinness, D., Nardi, D. and Patel Schneider, P. (2003), The Description Logic Handbook: Theory, Implementation and Applications, Cambridge University Press, Cambridge.

Bakry, S.H. and Alfantookh, A. (2010), "Toward building the knowledge culture: reviews and a KC STOPE with six sigma view", International Journal of Knowledge Society Research, Vol. 1 No. 1, pp. 4765.

Ball, L. and Harris, R. (1982), "SMIS members: a membership analysis", MIS Quarterly, Vol. 6 No. 1, pp. 1938.

Barden Fuller, C., Targett, D. and Hunt, B. (2005), "Outsourcing to outmanoeuvre: outsourcing redefines competitive strategy and structure", European Management Journal, Vol. 18 No. 3, pp. 28595.

Bartelsman, E., Bassanini, A., Haltiwanger, J., Jarmin, R., Scarpetta, S. and Schank, T. (2004), "The spread of ICT and productivity growth: is Europe really lagging behind in the new economy?", in Cohen, D., Garibaldi, P. and Scarpetta, S. (Eds), The ICT Revolution: Productivity Differences and the Digital Divide, Oxford University Press, Oxford.

Barthelemy, J. (2001), "The hidden costs of IT outsourcing”, Sloan Management Review, Vol. 42 No. 3, pp. 609.

Battré, D. (2008), "Caching of intermediate results in DHT based RDF stores", International Journal of Metadata, Semantics and Ontologies, Vol. 4 No. 3, pp. 18395.

Beasley, M., Bradford, M. and Dehning, B. (2009), "The value impact of strategic intent on firms engaged in information systems outsourcing", International Journal of Accounting Information Systems, Vol. 10 No. 2, pp. 7996.

Berners Lee, T., Hendler, J. and Lassila, O. (2001), “The semantic web”, Scientific American, Vol. 284 No. 5, pp. 3540.

Boyd, M., Huang, S.M., Jiang, J.J. and Klein, G. (2007), "Discrepancies between desired and perceived measures of performance of IS professionals: views of the IS professionals themselves and the users", Information \& Management, Vol. 44 No. 2, pp. 18895. 
Brown, M. and Heywood, J.S. (2005), "Performance appraisal systems: determinants and change", British Journal of Industrial Relations, Vol. 43 No. 4, pp. 65979.

Casado Lumbreras, C., Colomo Palacios, R., Gómez Berbís, J.M. and García Crespo, Á. (2009), "Mentoring programmes: a study of the Spanish software industry", International Journal of Learning and Intellectual Capital, Vol. 6 No. 3, pp. 293302.

Casado Lumbreras, C., García Crespo, A., Colomo Palacios, R. and Gómez Berbís, J.M. (2010), "Emotions and interpersonal skills for IT professionals: an exploratory study", International Journal of Technology Enhanced Learning, Vol. 2 No. 3, pp. 21522.

Chou, D.C. and Chou, A.Y. (2009), "Information systems outsourcing life cycle and risks analysis", Computer Standards \& Interfaces, Vol. 31 No. 5, pp. 103643.

Cole, K. (2001), Supervision: The Theory and Practice of First line Management, 2nd ed., Prentice Hall, Sydney.

Colomo Palacios, R., Gómez Berbís, J.M., García Crespo, A. and Puebla Sánchez, I. (2008), "Social global repository: using semantics and social web in software projects", International Journal of Knowledge and Learning, Vol. 4 No. 5, pp. 45264.

Colomo Palacios, R., García Crespo, A., Gómez Berbís, J.M., Casado Lumbreras, C. and Soto Acosta, P. (2010), "SemCASS: technical competence assessment within software development teams enabled by semantics", International Journal of Social and Humanistic Computing, Vol. 1 No. 3, pp. 23245.

Cross, J. (1995), "IT outsourcing: British petroleum”, Harvard Business Review, Vol. 73 No. 3, pp. 94102.

Curtis, B., Hefley, W.E. and Miller, S.A. (2001), People Capability Maturity Model, Version 2.0, CMU/SEI 2001 MM 01, Carnegie Mellon University, Pittsburgh, PA.

Davies, J., Lytras, M.D. and Sheth, A.P. (2007), "Semantic web based knowledge management", IEEE Internet Computing, Vol. 11 No. 5, pp. 1416.

Doig, S.J., Ritter, R.C., Speckhals, K. and Woolson, D. (2001), "Has outsourcing gone too far?", McKinsey Quarterly, Vol. 4, pp. 2437.

Drucker, P. (1959), Landmarks of Tomorrow, Harper \& Brothers, New York, NY.

Drucker, P. (1998), “The coming of the new organization”, Harvard Business Review, Vol. 66 No. 1, pp. 119.

Earl, M. (1996), “The risks of outsourcing IT”, Sloan Management Review, Vol. 37 No. 3, pp. 2632.

Faisal, M.N. and Banwet, D.K. (2009), "Analysing alternatives for information technology outsourcing decision: an analytic network process approach", International Journal of Business Information Systems, Vol. 4 No. 1, pp. 4762.

Fensel, D. (2002), Ontologies: A Silver Bullet for Knowledge Management and Electronic Commerce, Springer, Berlin.

Fensel, D. and Munsen, M.A. (2001), "The semantic web: a brain for humankind”, IEEE Intelligent Systems, Vol. 16 No. 2, pp. 245.

Fisher, S.L., Wasserman, M.E., Wolf, P.P. and Wears, K.H. (2008), "Human resource issues in out sourcing: integrating research and practice", Human Resource Management, Vol. 47 No. 3, pp. 50123.

Garavan, T. and McGuire, D. (2001), "Competencies and workplace learning: some reflections on the rhetoric and the reality", Journal of Workplace Learning, Vol. 13 Nos 3/4, pp. 14464.

García Crespo, A., Colomo Palacios, R., Gómez Berbís, J.M. and García Sánchez, F. (2010a), "SO LAR: social link advanced recommendation system", Future Generation Computer Systems, Vol. 26 No. 3, pp. 37480. 
García Crespo, A., Colomo Palacios, R., Gómez Berbís, J.M. and Mencke, M. (2009a), "BMR: benchmarking metrics recommender for personnel issues in software development projects", International Journal of Computational Intelligence Systems, Vol. 2 No. 3, pp. 25767.

García Crespo, A., Colomo Palacios, R., Gómez Berbís, J.M. and Mencke, M. (2009b), "SemOut Quote: using semantics for innovation offshore outsourcing management", International Journal of Management Information Systems, Vol. 1 No. 1, p. E3.

García Crespo, A., Colomo Palacios, R., Gómez Berbís, J.M. and Ruiz Mezcua, B. (2010b), "SEMO: a framework for customer social networks analysis based on semantics", Journal of Information Technology, Vol. 25 No. 2, pp. 17888.

Gonzalez, R., Gasco, J. and Llopis, J. (2005), "Information systems outsourcing reasons in the largest Spanish firms”, International Journal of Information Management, Vol. 25 No. 2, pp. 11736.

Gottschalk, P. and Solli Sæther, H. (2006), "Maturity model for IT outsourcing relationships", Industrial Management \& Data Systems, Vol. 106 No. 2, pp. 20012.

Goyal, P. and Metri, B.A. (2008), "The FIFTH perspective: extending the balanced scorecard for outsourcing", Journal of Information Technology Research, Vol. 1 No. 1, pp. 4756.

Grover, V., Cheon, M.J. and Teng, J.T.C. (1994), "A descriptive study on the outsourcing of information systems functions”, Information \& Management, Vol. 27 No. 1, pp. 3344.

Gruber, T.R. (1994), "Toward principles for the design of ontologies used for knowledge sharing", Journal of Human Computer Studies, Vol. 43 Nos 5/6, pp. 90728.

Gruber, T.R. (2008), "Collective knowledge systems: where the social web meets the semantic web”, Web Semantics: Science, Services and Agents on the World Wide Web, Vol. 6 No. 1, pp. 413.

Gómez Berbís, J.M., Colomo Palacios, R., García Crespo, A. and Ruiz Mezcua, B. (2008), "ProLink: a semantics based social network for software projects", International Journal of Information Technology and Management, Vol. 7 No. 4, pp. 392404.

Hefley, W.E. and Loesche, E.A. (2006), The eSourcing Capability Model for Client Organizations (eSCMCL): Part One, Model Overview, ITsqc Working Paper Series \# CMU ITSQC WP 06 001, IT Services Qualification Center, Carnegie Mellon University, Pittsburgh, PA.

Hernández López, A., Colomo Palacios, R., García Crespo, A. and Soto Acosta, P. (2010), "Trust building process for global software development teams: a review from the literature", International Journal of Knowledge Society Research, Vol. 1 No. 1, pp. 6683.

Hoecht, A. and Trott, P. (2006), "Innovation risks of strategic outsourcing", Technovation, Vol. 26 Nos 5/6, pp. 67281.

Huber, R. (1993), "How continental bank outsourced its 'Crown Jewels”, Harvard Business Review, Vol. 71 No. 1, pp. 1219.

Hurley, T. and Green, C. (2005), "Knowledge management and the nonprofit industry: a within and between approach", Journal of Knowledge Management Practice, p. 6.

Jackson, S. and Schuler, R.S. (2003), Managing Human Resources through Strategic Partnership, 8th ed., Thompson, Canada.

Johnson, M. and Senges, M. (2010), "Learning to be a programmer in a complex organization: a case study on practice based learning during the onboarding process at Google", Journal of Workplace Learning, Vol. 22 No. 3, pp. 18094. 
Kakabadse, A. and Kakabadse, N. (2002), "Trends in outsourcing", European Management Journal, Vol. 20 No. 2, pp. 18998.

Karreman, D., Sveningsson, S. and Alvesson, M. (2002), "The return of the machine bureaucracy? Management control in the work settings of professionals", International Studies of Management \& Organization, Vol. 32 No. 2, pp. 7093.

Kessler, I., Coyle Shapiro, J. and Purcell, J. (1999), "Out sourcing and the employee perspective", Human Resource Management Journal, Vol. 9 No. 2, pp. 520.

Kim, W., Chung, M.J. and Lloyd, J. (2006), "Automated outsourcing partnership management using semantic web services", paper presented at 9th International Conference on Computer Supported Cooperative Work in Design II, Coventry, UK, May 24 26, 2005, Lecture Notes in Computer Science, 3865, Berlin/Heidelberg.

Lacity, M. and Hirschheim, R. (1993), Information Systems Outsourcing: Myths, Metaphors and Realities, Wiley, Chichester.

Lanzenberger, M., Sampson, J., Rester, M., Naudet, Y. and Latour, T. (2008), "Visual ontology alignment for knowledge sharing and reuse", Journal of Knowledge Management, Vol. 12 No. 6, pp. 10220.

Lee, J.M., Huynh, M.Q., Kwok, R.C.W. and Pi, S.M. (2003), "IT outsourcing evolution, past, present and future", Communications of the ACM, Vol. 46 No. 5, pp. 849.

Loh, L. and Venkatraman, N. (1992), "Determinants of information technology outsourcing: a cross sectional analysis", Journal of Management Information Systems, Vol. 19 No. 1, pp. 728.

McDougall, P. (2004), "Competencies and workplace learning: some reflections on the rhetoric and the reality", Information Week, Vol. 22 No. 1015, pp. 4455.

McGuire, D. (2001), "Outsourcers fall short", Journal of Workplace Learning, Vol. 13 No. 4, pp. 14464.

Macris, A., Papadimitriou, E. and Vassilacopoulos, G. (2008), "An ontology based competency model for workflow activity assignment policies", Journal of Knowledge Management, Vol. 12 No. 6, pp. 7288.

Myloni, B., Harzing, A.W.K. and Mirza, H. (2004), "Host country specific factors and the transfer of human resource management practices in multinational companies", International Journal of Manpower, Vol. 25 No. 6, pp. 51834.

Naeve, A., Sicilia, M.A. and Lytras, M.D. (2008), "Learning processes and processing learning: from organizational needs to learning designs”, Journal of Knowledge Management, Vol. 12 No. 6, pp. 514.

Nieminen, P. and Takala, J. (2006), “Achieving better on time delivery performance with the help of internal dependencies in the production", International Journal of Management and Enterprise Development, Vol. 3 Nos 1/2, pp. 18190.

O’Leary, M. (1990), “The mainframe doesn't work here anymore”, ClO, Vol. 6 No. 6, pp. 779.

O'Sullivan, D. and Dooley, L. (2010), "Collaborative innovation for the management of information technology resources", International Journal of Human Capital and Information Technology Professionals, Vol. 1 No. 1, pp. 1630.

Owen, S. and Stupans, I. (2009), "Australian pharmacy programme experiential placements: comprehensive planning for assessment and evaluation”, Assessment \& Evaluation in Higher Education, Vol. 34 No. 5, pp. 57994.

Rebelo, T.M. and Duarte Gomes, A. (2011), "Conditioning factors of an organizational learning culture”, Journal of Workplace Learning, Vol. 23 No. 3, pp. 17394. 
Saunders, C. and Gebelt, M. (1997), "Achieving success in information systems outsourcing”, California Management Review, Vol. 39 No. 2, pp. 6377.

Scheir, P., Lindstaedt, S.N. and Ghidini, C. (2008), "A network model approach to retrieval in the semantic web”, International Journal on Semantic Web and Information Systems, Vol. 4 No. 4, pp. 5684 .

Shadbolt, N., Hall, W. and Berners Lee, T. (2006), “The semantic web revisited”, IEEE Intelligent Systems, Vol. 21 No. 3, pp. 96101.

Sharma, R.S., Ng, E.W.J., Dharmawirya, M. and Samuel, E.M. (2010), “A policy framework for developing knowledge societies", International Journal of Knowledge Society Research, Vol. 1 No. 1, pp. 2346.

Soto Acosta, P., Martínez Conesa, I. and Colomo Palacios, R. (2010), "An empirical analysis of the relationship between IT training sources and IT value", Information Systems Management, Vol. 27 No. 3, pp. 27483.

Trigo, A., Varajao, J., Soto Acosto, P., Barroso, J., Molina Castillo, F.J. and Gonzalvez Gallego, N. (2010), "IT professionals: an Iberian snapshot", International Journal of Human Capital and Information Technology Professionals, Vol. 1 No. 1, pp. 6175.

Vossen, G., Lytras, M. and Koudas, N. (2007), "Editorial: Revisiting the (Machine) Semantic Web: The Missing Layers for the Human Semantic Web”, IEEE Transactions on Knowledge and Data Engineering, Vol. 19 No. 2, pp. 1458.

Zineldin, M. and Bredenlow, T. (2003), "Strategic alliance: synergies and challenges: a case of strategic outsourcing relationship 'Sour”, International Journal of Physical Distribution \& Logistic Management, Vol. 33 No. 5, pp. 44964.

\section{About the authors}

Cristina Casado Lumbreras is an Adjunct Professor at Faculty of Education, Universidad Complutense of Madrid. She received her $\mathrm{PhD}$ in Psychology from the Universidad Autónoma of Madrid (2002). She has been working in several research institutions and universities since the 1990s including Universidad Autónoma of Madrid, Universidad Complutense of Madrid and Escuela de Administración de Empresas (EAE). Her research interests include human capital development, staffing along with emotions in organizational contexts.

Pedro Soto Acosta is a Professor of Management at the University of Murcia (Spain). He holds a $\mathrm{PhD}$ in Management Information Systems (MISs) and a Master's degree in Technology Management from the University of Murcia. He received his BA in Accounting and Finance from the Manchester Metropolitan University (UK) and his BA in Business Administration from the University of Murcia. He attended Postgraduate Courses at Harvard University (USA). His work has been published in journals such as the European Journal of Information Systems, the International Journal of Information Management, Information Systems Management, and the Journal of Enterprise Information Management, among others.

Ricardo Colomo Palacios is an Associate Professor at the Computer Science Department of the Universidad Carlos III de Madrid. His research interests include applied research in information systems, software project management, people in software projects and social and semantic web. He received his $\mathrm{PhD}$ in Computer Science from the Universidad Politécnica de Madrid (2005). He also holds a MBA from the Instituto de Empresa (2002). He has been working as software engineer, project manager and software engineering consultant in several companies including Spanish IT leader INDRA. He is also an Editorial Board Member and Associate Editor for several international journals and conferences and Editor in Chief of International Journal of Human Capital and Information Technology Professionals. Ricardo Colomo Palacios is the corresponding author and can be contacted at: ricardo. colomo@uc3m.es 
Patricia Ordóñez de Pablos is a Professor in the Department of Business Administration at the Faculty of Economics and Business of The University of Oviedo (Spain). Her teaching and research interests focus on the areas of strategic management, knowledge management, intellectual capital, organizational learning, human resources management and information technologies. She has published her papers in international leading journals (Computers in Human Behaviour, International Journal of Technology Management, Information Systems Management, Ergonomics and Human Factors in Manufacturing, etc.). She serves as Associate Editor of Behaviour and Information Technology journal. She is Executive Editor of the International Journal of Learning and Intellectual Capital and Editor in Chief of the International Journal of Strategic Change Management. 